\title{
Angiomatosis retinae
}

\author{
G. G. KEITH \\ North Middlesex Hospital, London
}

Von Hippel-Lindau disease or angiomatosis retinae is a rare condition that can present at any age but most commonly in the third decade (Duke-Elder and Dobree, I967). It is most probably present at birth in the form of rests of angioblastic cells that later proliferate to form the tumours; the early signs of dilated vessels are most probably secondary to the new vessel formation and not the cause of this formation. The most common site is in the temporal side of the retina near the equator. It is said to be bilateral in $5^{\circ}$ per cent. of cases and to occur equally in both sexes. It seems to be inherited as an autosomal dominant in 20 per cent. and is associated with central nervous system involvement in 20 per cent. of cases. The prognosis for an eye with this condition is generally thought to be bad, most progressing through the stages of haemorrhage and exudation to massive exudates giving the picture of Coats's disease with retinal detachment and ultimately glaucoma.

The following case is reported because the presentation was unusual, the site of the lesions was also unusual, being nearly at the ora serrata, and the lesions have not progressed over a period of 10 years.

\section{Case report}

A 50-year-old white man was first seen in June, 1962, complaining of "floaters" in the left eye. The visual acuity was $6 / 6$ in the right eye and $6 / 12$ in the left. The right eye was normal in all respects. In the left eye there was a mild anterior uveitis with a flare and cells in the anterior chamber and some vitreous haze. In the fundus could be seen some large vessels passing upwards from the disc towards some whitish tissue with surrounding pigmentation lying near the ora serrata between 12 and 2'oclock. Another area of choroido-retinal scarring could be seen at 6 o'clock. When the vitreous haze cleared some weeks later, a pinkish angioma could be seen in the area of scarring at I o'clock (Figure, overleaf), with the large feeding vessels passing into it. It was considered to be a haemangioblastoma (Hippel-Lindau tumour).

A full physical examination was carried out and no abnormalities were found. Skull and chest $x$ rays were normal. Serological tests for syphilis, toxoplasmosis, and brucellosis were negative.

Fluorescein angioscopy was carried out and the upper lesion fluoresced markedly. A formal angiography was carried out by Prof. D. W. Hill, who confirmed the fluorescence of the lesion and commented that the speed of blood flow in the feeding vessels was not increased.

The uveitis was considered to be due to inflammatory changes in the lesion and prednisolone Io mg. three times a day was given orally for 3 months until all signs of inflammation had settled.

Since then the lesion has remained unchanged and has caused no further inconvenience.

\section{Discussion}

Most authors consider that this condition has a bad prognosis for the eye, but many lesions do not give rise to any symptoms until the fourth or fifth decade (Duke-Elder and Dobree, 


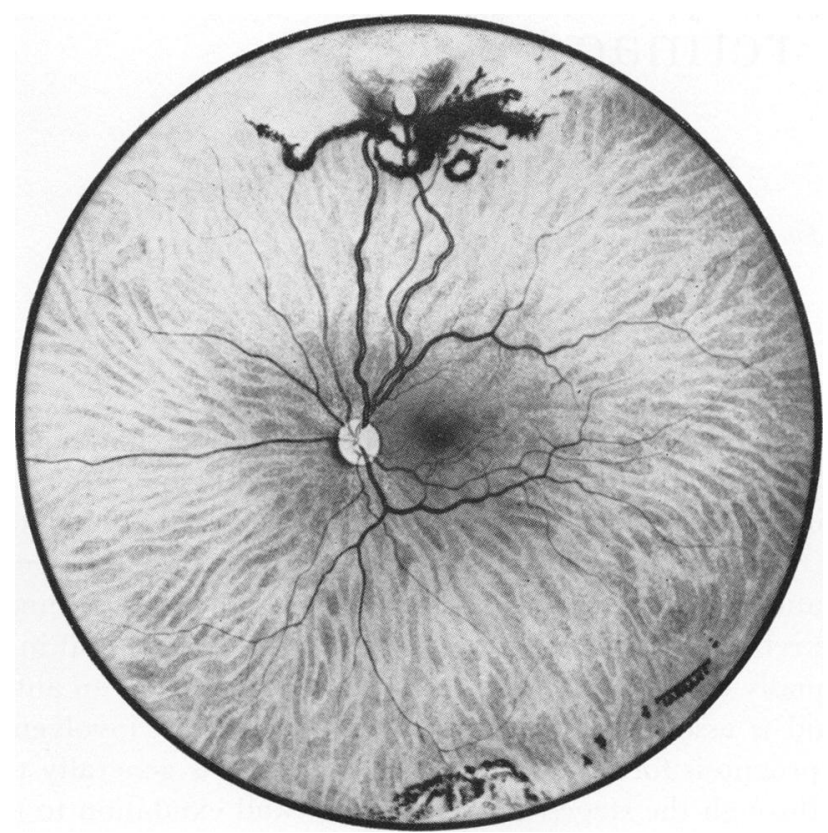

FIGURE Fundus appearance in a case of angiomatosis

I 967); they must presumably lie dormant until then and some possibly never give rise tơ symptoms, although there seem to be no reports of the lesion being found on routing examination. Daicker (1973), in his extensive study on the peripheral retina and ciliar zone, found no angiomata in his pathological material nor did he refer to them in his review of the literature of the pathological changes that occur in this region, so it is probabl rare for angiomata not to give rise to symptoms and also rare for them to occur at the or® serrata. Self-healing lesions have been reported previously (Rumbaur, I94I), but thes $\overrightarrow{\vec{E}}$ are also rare, and it would therefore seem that in general treatment with light coagulation or diathermy is advisable. But it should not be forgotten that sometimes the lesions de not progress, and a period of observation may be prudent before starting treatment.

\section{Summary}

A case of angiomatosis (Von Hippel-Lindau disease) in a 50-year-old man presented as aî anterior uveitis in the left eye which settled on treatment with steroids. The tumour was discovered when the vitreous haze cleared near the ora serrata between 12 and $\stackrel{\circ}{2}$ o'clock, and the diagnosis was verified by fluorescein angiography. The lesion has not altered during a period of ro years' observation and the visual acuity in the eye has remained at 6/12.

I am grateful to Mr. T. Tarrant of the Department of Medical Illustration, Institute of Ophthalmolog London, for the fundus painting.

\section{References}

DAICKeR, B. (1972) "Anatomie und Pathologie der menschlichen retino-ziliaren Fundusperipherie'?

Karger, Basel

DUKE-ELDER, S., and DOBREE, J. H. (1967) "System of Ophthalmology", vol. 1o, "Diseases of th

Retina", p. 741. Kimpton, London

rumbaur, w. (I941) Klin. Mbl. Augenheilk., 106, 68 